\title{
EL DESPERTAR DE LOS QUE DUERMEN: JUAN GÓMEZ BÁRCENA Y LA NUEVA NARRATIVA ESPAÑOLA POSTCRISIS
}

\author{
Mónica Poza Diéguez \\ Doctora por la Universidad de California, Davis \\ pozamo@gmail.com
}

RESUMEN: En el presente artículo analizo Los que duermen, un libro de relatos escrito por Juan Gómez Bárcena (2012). En mi análisis, conecto varias características de su narrativa con las expuestas por el autor en su prólogo para Bajo treinta (2013), una edición compilatoria de cuentos escritos por autores menores de treinta años. Como editor, Gómez Bárcena ofrece al lector una precisa descripción del panorama literario español actual con respecto a autores jóvenes, cuya escritura se sitúa en el marco de la crisis económica de 2008. En Los que duermen, Gómez Bárcena toma el lenguaje como la herramienta principal para definir al ser humano y explorar su naturaleza en conexión con la Historia, la Filosofía y los mitos. Como resultado, nos muestra finales alternativos a los relatos místicos y reflexiones inquietantes sobre la evolución humana, mediante el uso de la ucronía, la microhistoria y la reflexión sobre la degradación del signo lingüístico.

PALABRAS CLAVE: simulacro, signo, microhistoria, ucronía, extinción

\begin{abstract}
In this article I analyze a short-stories fiction collection titled Los que duermen, written by Juan Gómez Bárcena in 2012. In my analysis I connect some elements of his narrative shown here with those underlined by the author in the Prologue for Bajo reinta (2013), a compilation of short stories written by your writers in their 20's. As editor, Gómez Bárcena gives to his readers an accurate description on Contemporary Spanish Literature's current trends. He portraits the state of the art after the financial crisis of 2008. In Los que duermen, Gómez Bárcena takes the language as the main tool to define the human being and to explore its nature in connection with History, Philosophy, and Myths. As a result, he develops optional endings to traditional mythological stories, and offers the reader disturbing reflections on human evolution, through the use of uchronia, the microhistory, and the reflection on the decay of the linguistic sign.
\end{abstract}

KEYWORDS: simulacra, sign, microhistory, uchronia, extinction

Juan Gómez Bárcena (Santander, 1984) es el autor de Los que duermen (Salto de página, 2012), galardonado con el Premio Tormenta al Mejor Autor Revelación en 2013, ha cosechado importantes críticas en suplementos literarios de reconocido prestigio, como $E l$ Cultural o Babelia. Licenciado en Literatura Comparada, Teoría de la Literatura y Filosofía e Historia, Gómez Bárcena es autor de varias novelas (El héroe de Duranza, 2002, Farmer Stop, 2010), es también el editor de la antología de jóvenes autores españoles Bajo Treinta (2013). Ha recibido numerosos premios, como el "Ojo crítico" y "Ciudad de Alcalá 2015" 
por la novela El cielo de Lima (Salto de página, 2014) y diversas becas, de las cuales la más reciente es la que otorga la Real Academia de España en Roma, con una estadía de un año en dicha ciudad, entre 2016 y 2017.

En las siguientes páginas me propongo analizar su libro de relatos Los que duermen, así como su prólogo en la antología de Bajo Treinta, a fin de esbozar la imagen de los jóvenes autores españoles, cuya obra se enmarca en los años posteriores al comienzo de la crisis económica surgida en 2008.

En su prólogo para Bajo Treinta, Gómez Bárcena asume el reto de explicar una supuesta escasez productiva entre los jóvenes autores españoles del primer cuarto del siglo XXI. Personalmente, creo que su prólogo delinea perfectamente el estado de la cuestión. Más que de una ausencia de grandes autores, lo que sucede en el panorama literario español se resume a un desapego de los jóvenes autores por los circuitos editoriales más comerciales. ${ }^{1}$ La literatura de estos escritores no parece plegarse a ese homogéneo mercado en el que son las propias editoriales las que, a golpe de contrato, aúpan a determinados escritores bajo la máscara de los premios millonarios amparados en etiquetas prefabricadas en los departamentos de marketing.

No deben ser estas editoriales las que determinen el panorama literario ${ }^{2}$ de todo un país, como sucedió en el pasado. No pueden serlo porque el contexto cambió. Nuevas editoriales mucho más pequeñas se han ido abriendo paso en los últimos años, en muchos casos como iniciativas de jóvenes que comparten inquietudes y vicisitudes, cuando no la edad de los propios autores a los que editan, tal y como menciona Angel García Galiano (Gómez Bárcena, 2013: 8). Y tampoco pueden serlo porque las redes sociales, Internet, han transmutado radicalmente la relación entre autor, editor, distribuidora y lector. Alteradas esas reglas del juego, nada puede volver a ser como era. El círculo se ha roto, se ha abierto y se ha hecho más poroso, y en ese estado de cosas peligra la confortable atmósfera protegida en la que muchos autores han desarrollado sus carreras. Ese parece haber sido el detonante de la disputa $^{3}$ que ha provocado la publicación de dos antologías, una de ellas, Bajo Treinta. Y sin embargo, al igual que ha sucedido en el ámbito de la música o del cine, efectivamente se ha abierto una línea al margen de los circuitos oficiales, mucho más interesante por su

\footnotetext{
1 "Y es que no deja de ser sorprendente que la sociedad posmoderna, tan adiestrada en desenmascarar los discursos del poder, tan capaz de adivinar sutiles juegos de dominación en la publicidad y en las prácticas domésticas más corrientes, no haya adquirido todavía la conciencia de que el circuito editorial es ante todo una industria, con intereses propios que pueden coincidir o no con los de la literatura" (Gómez Bárcena, 2013: 6).

2 "La industria del libro no debe ser tomada como un termómetro imparcial de la calidad, pues en mayor o menor medida todas las editoriales componen sus catálogos bajo el efecto de distintas presiones" (Gómez Bárcena, 2013: 7).

${ }^{3}$ Véase la reseña que el profesor de Literatura Española Contemporánea en la Universidad Autónoma de Barcelona, Fernando Valls, dedicó a Última temporada. Nuevos narradores españoles (Lengua de Trapo, 2013), de Alberto Olmos, y a Bajo treinta. Antología de nueva narrativa española, publicada en El País, el 30 de noviembre, quizás escrita con un cierto apresuramiento, pues obvia las razones que se dan en el prólogo para no incluir a autores que ya sobrepasan los treinta años, motivo por el que la antología se titula Bajo treinta: "De haber ampliado un poco más los márgenes hasta englobar a los nacidos — por ejemplo — en 1977, el resultado hubiera sido distinto y creo que mejor, al haber podido aparecer Andrés Neuman, Miguel Serrano Larraz, Irene Jiménez, Elvira Navarro y Lara Moreno" (Valls, 2013: 77). Asimismo, Valls obvia la explicación que Gómez Bárcena da con respecto a la inexistencia de una generación literaria, como rasgo característico de estos autores jóvenes: "Los criterios de inclusión, siendo siempre caprichosos, también deberían intentar ser lo menos arbitrarios posible para que el conjunto adquiera una cierta representatividad literaria y, sobre todo, entidad estética" (2013:77). De cualquier manera, se agradece en la reseña el punto crítico, pero se echa en falta el rigor filológico y, sobre todo, son lamentables algunas expresiones del tipo: "Aunque para verdes, los antólogos; el primero, un fama resabiado y pinturero, obsesionado por los premios y los adelantos; y el segundo, un cronopio ingenuo que a menudo cae en el empacho" (2013:77).
}

Mónica Poza Diéguez: "El despertar de los que duermen: Juan Gómez Bárcena y la nueva narrativa española postcrisis" 
desvinculación de los intereses puramente comerciales.

Tal y como menciona Gómez Bárcena en su prólogo, los jóvenes autores españoles reúnen todas las características para que las grandes editoriales no deseen ni acercarse a su obra. Para empezar, son de verdad jóvenes, lo cual llama la atención en un país donde algunos escritores ya consagrados llevan recibiendo ese apelativo desde los años $90 .{ }^{4}$ Además, no desean pertenecer a ese constructo artificioso que son las generaciones, ${ }^{5}$ y es que tampoco tienen motivos para hacerlo, pues su literatura es completamente heterogénea, a pesar de que se den algunos patrones comunes. Uno de ellos, según Gómez Bárcena, es la temática acerca de la familia o las relaciones de familia, mientras que el otro es la crisis, no solo económica, sino también la de aquellos valores conforme a los cuales estos autores fueron formados. $\mathrm{Y}$ esto no es de extrañar, ya que si de algo pueden presumir nuestros jóvenes, escritores o no, es de las dificultades que siempre han tenido para emanciparse, lo que ahora se ha agravado sustancialmente con el derrumbe económico, institucional e ideológico. ${ }^{6}$ Otro rasgo visible del grupo es que no parecen respetar los géneros, algo que puede deberse a varios factores que no entraré a analizar aquí, por cuestiones de espacio. También es evidente la variedad de estilos, y se observa una disminución de la influencia del realismo sucio americano y el regreso de algunos autores a una narrativa de corte más clásico y de tradición española. En todos estos rasgos con los que Gómez Bárcena describe el panorama literario español, yo veo una suerte de autorretrato, pues como se verá a continuación, Los que duermen cumple punto por punto estas mismas características: heterogeneidad de estilos, cierto desapego por los géneros, una constante presencia del entorno en crisis, una suerte de derrumbamiento sistémico y ontológico. Y, por último, cumple con el hecho de que la edición del libro se lleve a cabo en una editorial pequeña, perteneciente al grupo Siglo XXI, Salto de Página, que poco a poco va dando excelentes frutos, como el presente libro, que paso a analizar.

Los que duermen es un libro de relatos interconectados entre sí, de modo que conforman una unidad diversa en cuanto a personajes, temática y estilos, y cuyo epicentro lo constituye una reflexión acerca del ser humano y su evolución a través de los siglos. A lo largo de sus páginas se encuentran innumerables referencias bibliográficas, así como el empleo de múltiples recursos estilísticos que lo conectan con la literatura oral y los relatos folklóricos tradicionales, la documentación histórica, pero también con el mundo literario

\footnotetext{
${ }^{4}$ Gómez Bárcena menciona los casos de Andrés Neuman (1977), autor ya consagrado, considerado “joven promesa" al ganar el Premio Herralde en 1999, y Sara Mesa (1976), finalista en 2011 y a la que la prensa catalogó igualmente como "joven promesa" (Gómez Bárcena, 2013: 7).

5 "Sospechamos que la supuesta homogeneidad estética de las generaciones del pasado es en parte una construcción de la crítica, que asesina la diversidad sobredimensionando las afinidades y soslayando las excepciones para captar un supuesto clima de época" (Gómez Bárcena, 2013: 13).

6 "Una solución interesante para explicar esta hipertrofia de lo familiar y esta ausencia del panorama político es suponer que ambos fenómenos están interrelacionados. Al fin y al cabo, uno de los efectos más evidentes de la crisis ha sido incrementar nuestra desconfianza por el espacio público y sus instituciones; cabe suponer por tanto que este retorno a la mínima unidad política, la familia, es de hecho la única alternativa del individuo en un mundo en el que la solidaridad colectiva y el modelo de estado en su conjunto han fracasado. Como respuesta a ese simulacro de globalización de las finanzas que nos ofrecía el capitalismo, que a la postre resultó sólo una globalización de las finanzas y de una ideología dominante, la sociedad podría estar concentrándose cada vez más en recorrer el camino inverso. Por otro lado, si pensamos en el preocupante incremento de la edad de emancipación de los jóvenes en la última década, no resulta nada raro que los narradores menores de treinta años, muchos de ellos probablemente aún en casa de sus padres o dependiendo en algún sentido de su apoyo, perciban como un tema crucial los conflictos familiares" (Gómez Bárcena, 2013: 16).
}

Mónica Poza Diéguez: "El despertar de los que duermen: Juan Gómez Bárcena y la nueva narrativa española postcrisis" 
propio de las Crónicas de Indias, el relato histórico, la ciencia ficción, el mundo de los mitos y las leyendas o los textos sagrados procedentes de diversas tradiciones religiosas, por citar solo algunos ejemplos. Estamos, por tanto, ante un libro que, pese a su brevedad y lo ameno de las historias que se narran en él, es complejo en cuanto a forma y significado.

El primero de los relatos comienza imitando el estilo de un documento histórico, el relativo a las crónicas que los viajeros al Nuevo Mundo referían. Se trata de un "Extracto del diario de navegación de Juan Gómez de Carandía, capitán de la nao San Telmo”, fechado en el año 1564, que se encuentra incompleto en su inicio. El paralelismo entre el nombre del autor y el de este narrador en primera persona supone un juego de niveles de realidad que se dará a lo largo de la obra con el propósito de mezclar la Historia con historias o microhistorias alternativas, posibles, a modo de ucronías, a través de las que el concepto de verdad no se revela como absoluto, sino como ente plural, relativo y diverso que conforma una unidad vasta y compleja, casi siempre incomprensible para el ser humano.

Este primer relato, titulado "Cuaderno de bitácora", comienza in medias res con la nave San Telmo perdida en medio del mar. Un mar que se ha configurado como espacio y tiempo a la vez. Este irrumpe en el relato como fuerza que impele y como lugar de transición. Poco sabemos de las circunstancias que rodean a quienes viajan en la nave San Telmo, pero el viraje producido por el mar, tras una tempestad, marca el comienzo del adentramiento de los personajes en otras coordenadas espacio-temporales, que atañen al suceso (y empleo aquí este término, también en el sentido en que lo hace Bajtín [1989: 247-248]) y a la "maravilla".

El motivo cronotópico de la tormenta en el mar proviene de una larga tradición ligada a los mitos y a la ficción. Ulises creyó tocar tierra, por fin, cuando el designio de los dioses lo lanza de nuevo a la aventura, por medio de un golpe de mar que cambia su destino. Y una tempestad es la que desplaza a los protagonistas de la obra de Shakespeare a una isla en la que se darán episodios de magia. Por lo general, las tempestades "otorgan un rol activo a los mares al poder torcer el rumbo, vital y de navegación, de los hombres" (Asiss González, 2015: 143). Así que, podría decirse de alguna forma que el cronotopo del camino, con el comienzo del viaje y de las aventuras del héroe, le deben mucho al mar y sus tempestades, que serían una variante del mismo.

Este mar tempestuoso constituido en espacio de tránsito (similar al cronotopo del umbral desarrollado por Bajtín) proporciona el adentramiento del héroe en el espacio-tiempo de lo mítico, de la ficción. La tempestad marina podría, de hecho, incorporarse a una amplia lista de espacios estrechos y anchos que sirven para "pasar a la otra orilla", tal y como entiende Octavio Paz ese proceso por el que nos trasladamos al lugar y tiempo propios de la poesía (1967: 117-136), y que pone a prueba las habilidades y la capacidad de supervivencia del héroe. Son ejemplos bien conocidos por el lector: el túnel por el que desciende Alicia para llegar al mundo maravilloso, la tienda del señor Koreander, en La historia interminable, en cuya puerta cuelga un letrero que reza "LIBROS DE OCASIÓN. Propietario: Karl Konrad Koreander", lo primero que lee el lector, ya en el mismo prólogo de la obra. Un elemento sorpresivo, además, es este letrero que se presenta del revés, porque se entiende que, al abrir el libro y comenzar a leer, uno "ya está dentro" del negocio del señor Koreander, o lo que es lo mismo, del espacio ficcional de la novela escrita por Ende. También el tornado que atrapa a Dorothy, la protagonista de $E l$ mago de $O z$, ejerce esta función. La lista de espacios de tránsito en la literatura, como bien explica Pedrosa, está bien nutrida de ellos: desde Prometeo, Jasón, Orestes, Ulises, Teseo, Edipo, Don Quijote al descender a la cueva de Montesinos, Alí Babá, Sigfrido, Don Juan Tenorio, etc., (2003: 37-63). "Cuaderno de 
bitácora" arranca con una tormenta que desplaza el barco, sin rumbo conocido, al sur (con todo lo que el sur conlleva, también, en el imaginario popular y tradicional). Con esta tempestad no solo se propicia el marco adecuado a este primer relato, sino que, al estar engarzados todos los que componen el libro, sucede como con el letrero de la tienda del señor Koreander; esta supone, además, el umbral del lector que, gracias a ella, se asoma al abismo y se interna en el territorio fantástico que propone toda la obra.

Aunque realizar un análisis narratológico detallado del espacio y el tiempo, de toda la obra, conllevaría un extenso artículo que no cabe en las presentes páginas, creo que puede afirmarse, a tenor de lo aquí ya expuesto, que Juan Gómez Bárcena emplea sabiamente lo que Bajtín denominó como "el tiempo de la aventura de tipo griego" (1989: 244), ya que a pesar de que cada relato es independiente y está conformado como tal, el hecho de trabajar con un universo cronotópico que responde a tales características le permite que, a la vez, cada uno de ellos "parezca" una aventura conectada con la anterior, a la vez que favorece la repetición de esos sucesos, con formas algo diferentes debido a que "la relación entre el espacio y el tiempo no tiene aquí, por decirlo así, un carácter orgánico, sino puramente técnico (y mecánico)" (Bajtín, 1989: 252). El hecho de que las tramas generales de cada relato se den en diferentes contextos o coordinadas espacio-temporales diversas no impide que haya una transferencia de las aventuras, ya que "el cronotopo de la aventura se caracteriza por la ligazón abstracta entre el espacio y el tiempo, por la reversibilidad de los momentos de la serie temporal y por la transmutabilidad del mismo espacio" (Bajtín, 1989: 253). Esto permite que no haya un orden cronológico lineal que recorre las diferentes historias conforme se avanza en la lectura del libro, sino que algunas de ellas pueden darse en el siglo XVI, como sucede al comienzo del libro con "Cuaderno de bitácora", mientras que otras propuestas a mitad del libro suceden en el medievo, como es el caso de "La virgen de los cabellos cortados". Asimismo, este carácter abstracto de la aventura permite que también se transpongan las mismas historias en lugares diferentes, como se ve en los ejemplos que aportaremos en este análisis, pertenecientes a "Fábula del tiempo" y "El mercader de betunes".

Los primeros párrafos en "Cuaderno de bitácora" ofrecen la verosimilitud propia de los documentos históricos: "[...] tras lo cual la corriente nos arrastró hacia el Suroeste, no menos de doscientas leguas según mis cálculos, de tal manera que muy difícilmente podían hacerse cábalas sobre la parte del mundo en que nos encontrábamos" (Gómez Bárcena, 2012: 9). La peculiar naturaleza de las crónicas americanas en la época de la conquista española permite al autor introducir lo fantástico de manera progresiva, sin dañar la verosimilitud del dato histórico y antropológico, propio de los textos escritos por los exploradores. La palabra empleada a tal fin es "maravillas", en clara conexión con el concepto de "maravilla medieval": "Un solo volumen no bastaría para consignar las maravillas que presenciamos durante las doce semanas que erramos por mares ignotos, ni para dar cuenta del aspecto y las costumbres de tan dispares pueblos como nos acogieron con su hospitalidad o sus flechas" (Gómez Bárcena, 2012: 9). Ya inmersos en el terreno de la ficción, el lector sigue la ruta de la nave que, arrastrada por la fuerza de una tormenta, al igual que sucediera en La tempestad de Shakespeare (y en innumerables relatos de aventuras), arribará a la extraña tierra de las Antípodas, en que se da el mundo al revés, pues los indios se comportan como occidentales y los colonos españoles son los esclavos. De allí huyen rápidamente para acabar en la isla de los nativos biroches.

La infuencia de obras como Los viajes de Gulliver es evidente en esta parte del relato,

Mónica Poza Diéguez: "El despertar de los que duermen: Juan Gómez Bárcena y la nueva narrativa española postcrisis" 
que también contiene un aire oriental, y en el que se nos narran las peripecias de los exploradores en una tierra en la que la moneda de cambio es el propio lenguaje. La codicia y la soberbia desencadenarán el castigo que acabará con los colonizadores, en una suerte de justicia poética o ajuste de cuentas con la Historia. Incapaces de comprender el valor sagrado de la poiesis o de intuir, tal y como mencionaría Foucault, que la facultad de acceder al lenguaje y su control implican de por sí el acceso al conocimiento y al poder, los españoles perecerán. En la sociedad isleña biroche los más pobres exhiben un pobre uso del lenguaje y una escasa habilidad para adquirir nuevas palabras, mientras que el Emperador, el máximo poder en la jerarquía social, posee todo el léxico, y nadie puede pronunciar su nombre. Es evidente que Gómez Bárcena alude aquí al carácter sacro del lenguaje, pues en el libro la impronunciabilidad de un nombre o de una escritura está siempre unida a lo divino, y es un rasgo que se repetirá en varios relatos. Volveré más tarde sobre este asunto. Por el momento, solo diré que los españoles protagonistas de "Cuaderno de bitácora" creen engañar al Emperador al proporcionarle los nombres de las tierras españolas y europeas (y al hacerlo, en realidad le ofrecen sin saber cada lugar físico, al menospreciar el valor de la palabra) a cambio de oro y joyas, objetos que no saciarán ni el hambre ni la sed, una vez que se encuentren en alta mar, materia esta del tercer relato, "Cuaderno de bitácora II".

La segunda historia, "Fábula del tiempo", está concebida al estilo de un cuento tradicional de raíces orales y comienza con el narrador en tercera persona: "Cada vez que un forastero habla del paso inexorable de los años o lamenta la imposibilidad de trocar nuestro destino, el bardo toma la lira y canta la historia de la joven reina Bandica, que por amor a un muerto concibió la locura de viajar en el tiempo" (Gómez Bárcena, 2012: 15). El viaje iniciático en el tiempo con el protagonista como peregrino se repetirá en varios relatos más, casi siempre con la circularidad como forma estructural básica y la consumación del espacio como un topos mítico. También el rey Aktasar, protagonista del tercer relato, envía viajeros a lomo de una mula vieja y mágica a conocer el futuro y el pasado para adelantarse así a cualquier acontecimiento, con conocimiento de causa. Y Aquiles también peregrina, en este caso, para huir de su destino mítico. La Historia como eterno retorno y la interconexión entre los relatos se evidencian en párrafos y situaciones comunes, en clara alusión a un inconsciente colectivo, a los arquetipos culturales y a la elaboración literaria de los relatos orales y sus diferentes versiones. En este segundo relato, "Fábula del tiempo", se nos dice que en su viaje la reina Bandica:

[...] prosiguió su marcha hacia el sol naciente. En su camino atravesó llanuras infinitas en las que descubrió la soledad y aldeas miserables en cuyas chozas comprendió la pobreza. Por todas partes, encontró ruinas y hombres que arañaban los frutos de la tierra con su esfuerzo. La reina conoció también el hambre y se vio obligada a mendigar raciones de agua y pan. (Gómez Bárcena, 2012: 17)

El mismo párrafo se repite en el sexto relato titulado "El mercader de betunes", que tiene como protagonista a Aquiles, quien huye de su enfrentamiento con Héctor, en el que por fuerza ha de morir, y acaba por adoptar la identidad de un simple mercader de betunes para llevar una vida anodina y mediocre:

Pasan los días y Aquiles prosigue su marcha hacia el sol naciente. En su camino cruza desiertos en los que conoce la soledad y aldeas miserables en cuyas chozas arruinadas comprende la pobreza. Por todas partes encuentra ruinas y hombres que arañan los frutos de la tierra con su esfuerzo. Conoce también el hambre, y se ve obligado a mendigar raciones de pan y agua. (Gómez Bárcena, 2012: 49) 
Las ruinas, mencionadas en las dos citas anteriores, también se repiten a lo largo del libro. Por una parte, las ruinas nos retrotraen a las antiguas civilizaciones retratadas en los relatos, con lo que crean un marco y un estilo concretos. Por otra, la ruina es la evidencia de la guerra, del exterminio, de la característica más definitoria de un ser humano que en vano se busca y se piensa a sí mismo sin comprender. Finalmente, la ruina explicita el fracaso de ese ser que se ha forjado por medio del lenguaje. El concepto de ruina empleado aquí por Gómez Bárcena le debe mucho al ya delineado por Walter Benjamin ${ }^{7}$ (al que, por cierto, se menciona en el relato que da título al libro, "Los que duermen"). Allí, el protagonista y narrador, un celador del museo en el que se guardan momias (otra figura que aparece en otros relatos a su vez) conversa con un joven y conocido historiador:

Luego me preguntó qué opinaba sobre las momias. Me encogí de hombros. "No soy químico ni historiador", contesté. Él dio otro mordisco a su bocadillo y añadió, como si no me hubiera escuchado: "Ellas son nuestra oportunidad de deshacer los errores del pasado". Yo dije que sí, que desde luego lo eran, aunque no tenía ni idea de a qué se refería. Luego dijo otras muchas cosas que no entendí. Habló de la Historia, de un tal Benjamin y también de un ángel que caminaba de espaldas para mirar fijamente todo lo que destruía a su paso. "Eso hace el Ángel de la Historia", dijo, "repara las injusticias del pasado, trae hasta el presente la memoria de los vencidos. El tiempo acaba poniéndolo todo en su lugar". Yo dije que pensaba exactamente lo mismo y continué con mi trabajo. (Gómez Bárcena, 2012: 91)

Y eso es lo que precisamente lleva a cabo Gómez Bárcena en este libro. Sus cuentos conforman una cápsula en la que el tiempo — pasado, presente y futuro - se ha detenido, pero dentro de la cual es posible recorrer el decurso histórico hacia atrás y hacia adelante, tal y como lo hace el rey Aktasar gracias a su mágica mula. El autor consigue esta petrificación de la Historia con la introducción decadente de lo alegórico, pues todo el universo que plasma contiene raíces alegóricas.

Si tal y como afirma Octavio Paz, "el hombre es hombre gracias al lenguaje, gracias a la metáfora original que lo hizo ser otro y lo separó del mundo natural" (1967: 34), lo que lleva a cabo Gómez Bárcena es mostrar una evidente degradación del signo, y por tanto, del ser. Ya se comentó aquí la reacción de los colonos españoles en "Cuaderno de bitácora". El lenguaje, convertido en moneda de cambio por los biroches, acaba por ser objeto de burla, como consecuencia de la incapacidad que padecen los occidentales para entender su naturaleza. Lo sagrado, manifiesto por medio del lenguaje biroche, acaba por ejecutar en ellos una suerte de castigo divino en "Cuaderno de bitácora II".

En "La leyenda del rey Aktasar" se le ofrecen al lector variantes legendarias acerca de la extinción del pueblo cairo. Y si bien en todas ellas se alude a la pérdida de la fe en sus dioses paganos, Itata y Axime, ligados conceptualmente a las ideas del yin y el yang, en las dos últimas versiones referidas se constata la pérdida de la fe en el signo, en su propio lenguaje. Es llamativa la última leyenda en la que se refiere el naufragio de una galera romana junto a las costas del Mar Negro, cargada con toda suerte de riquezas y objetos que impusieron la moda del Imperio Romano entre los cairos, hasta tal punto que olvidaron sus propias costumbres y hasta su lengua:

Cuenta la leyenda que la moda se hizo tan popular que a los pocos años nadie recordaba las costumbres que estilaban sus antepasados, ni se conocía el modo correcto de sazonar un guisado cairo. Las propias palabras de su lengua, aquella jerga que nunca aprendieron a poner por escrito, se disiparon lentamente en el viento - como sus dioses; como sus glorias - y su

${ }^{7}$ Veáse el capítulo "Alegoría y Trauerspiel", de Walter Benjamin (2006: 375-408).

Mónica Poza Diéguez: "El despertar de los que duermen: Juan Gómez Bárcena y la nueva narrativa española postcrisis" 
idioma mutilado se plagó de palabras latinas que arrastraban un fuerte acento dacio. Olvidado su dialecto, fue inevitable olvidar con él el recuerdo de que alguna vez habían cabalgado una yegua sagrada. [...] Aprendieron a hablar un latín más perfecto que el hablado en Roma. Que marcaron tendencia en la moda [...] y que, con el tiempo, olvidaron que una vez fueron cairos. También dice que ellos, y no otros, fueron los últimos romanos que cayeron defendiendo Roma en el asedio final del bárbaro Odoacro en 476. (Gómez Bárcena, 2012: 33-34)

A su vez, el error fatal que comete (entre muchos otros) el caudillo guti Urkadunna, en el relato titulado "Zigurat", consiste en no comprender la inscripción hallada durante una de las guerras del Golfo por las tropas americanas cuatro mil años después, en las paredes del Zigurat de la capital de Acad, la ciudad que sus tropas destruyen y saquean sin misericordia. También en este cuento, los acadios son capaces de prever el futuro mirando las entrañas de los bueyes que sacrificaban a la diosa Isthar. Todo ese conocimiento solo le es revelado a Urkadunna una vez que ya se encuentra dentro del Zigurat, sin sospechar que este había de ser su tumba, desde el principio de los tiempos. Allí, en línea cronológica, Urkadunna observa imágenes de un mosaico que para él carecen de un significado concreto, pero que poco a poco se le revelan, a medida que la línea cronológica se acerca a su presente. El lenguaje pictográfico, el jeroglífico, las imágenes sagradas le auguran su final, sin que acierte a entender: "Vio un hombre atrapado en una cámara sellada, sacudido por los últimos estertores de la sed o el hambre, y no pudo asociar la escena a ningún recuerdo" (Gómez Bárcena, 2012: 66).

Urkadunna llega a ver al rey Aktasar caminando a lomos de su vieja y mágica mula, a las tropas americanas cruzando el desierto hacia Bagdad, y previsualiza un mundo distópico dominado por robots, referencia directa al último capítulo del libro, La espera. Otro final le hubiera aguardado de haber podido descifrar la inscripción en la entrada del Zigurat: "Amada diosa Ishtar/ si nosotros los acadios hemos de morir y desaparecer/ bajo la arena/ haz que los salvajes guti y su caudillo Urkadunna/ mueran y desaparezcan también/ con nosotros" (Gómez Bárcena, 2012: 63).

Todo en Los que duermen tiende a la ruina, a la imagen de lo ya destruido que guarda en sí un coágulo de Historia que no sabemos interpretar y al que le otorgamos un sentido sacro e indescifrable tras el que se oculta no solo lo divino, sino más importante aún, el ser humano. Hasta tal punto es el lenguaje la esencia del hombre, que el relativismo o la perversa manipulación de las palabras conduce a una aparente paradoja que acaba por ser tautología.

"El regreso" constituye el comienzo de otra línea paralela en el libro, la del simulacro. En él, se nos cuenta la historia de una mujer adúltera que expía su pecado con el sacrificio que le impone su comunidad. Como otros pecadores, es forzada a emprender un peregrinaje hasta la laguna en la que morirá tras habérsele concedido la gracia de verle el rostro a la Diosa. Durante el viaje la protagonista alcanza un conocimiento superior que le lleva a entender ese horror sagrado que la hará trascender. El rostro de la Diosa acaba por ser un espejo que refleja absolutamente todo. Esta idea de la unidad total, compuesta por elementos fractales, representa la propia idea sobre la que se ha forjado estructuralmente el libro.

Más tarde, en "La virgen de los cabellos cortados", se nos narra cómo siglos después y tras encontrar en ese mismo lago su cuerpo momificado, el fanatismo religioso de la Europa medieval lleva a la comunidad germana de Sylt-Host a nombrar a la adúltera como la santa patrona de su pueblo, en un claro error de interpretación. Esta misma momia aparecerá en el museo histórico del cuento "Los que duermen", junto con la del Hombre de Gundelröse, protagonista del relato "El padre fundador de Alemania", en el que asistimos a la 
deformación intencionada y malévola del discurso histórico llevada a cabo por los nazis para crear su universo ideológico racista ario, sustentador de un régimen violento y despiadado. Se establece así un paralelismo entre la construcción de discursos de poder, así como la reificación de materiales simbólicos en beneficio de la manipulación. La ruina benjaminiana deviene en simulacro, entendido este en el sentido en que lo concibió Baudrillard para delinear una traza genética de la violencia.

En "Hitler regala una ciudad a los judíos", Gómez Bárcena aborda el caso histórico del campo de concentración de Theresienstadt, en Checoslovaquia. Es evidente que este capítulo constituye el momento álgido en que el signo es distorsionado, en que este pierde todo su valor, pues Hitler convierte el campo de concentración en una suerte de parque de atracciones, con la intención de salvar la inspección que la Cruz Roja lleva a cabo. Al igual que sucede en "Bienvenido Mr. Marshall", se construye en Theresiendstadt un espacio teatral que restituya lo que una vez fue la vida real de los judíos en sus ciudades y pueblos. Se elimina a los enfermos, se obliga a comer a los sanos, se levantan oficinas, teatros de cartón piedra, se obliga a sonreír, es decir "Se borra todo y se vuelve a empezar. La restitución del original difumina la exterminación" (Baudrillard, 2007: 28) al tiempo que el relato denuncia la hipócrita inoperancia de las instituciones en un sistema podrido, así como la falaz y vergonzosa neutralidad que mantuvo Suiza durante los oscuros años del régimen nazi.

La realidad de Theresiendstadt queda demarcada por un lenguaje desprovisto de vida. La degradación del signo es absoluta, completamente desposeído de su naturaleza original se ve reducido al anquilosamiento propio de la fórmula burocrática y administrativa pues, tal y como menciona Baudrillard, "Después de Maquiavelo los políticos quizás han sabido siempre que el dominio de un espacio simulado está en la base del poder, que la política no es una función, un territorio o un espacio real, sino un modelo de simulación cuyos actos manifiestos no son más que el efecto realizado" (2007: 33). Así, en el sistema nazi, esta idea es llevada a tal extremo que el sujeto queda descarnadamente desposeído de su humanidad. Las víctimas pasan a formar parte de un decorado monstruoso, convertidos en meros números, mientras que sus asesinos pasan a engrosar la cadena de funcionarios de un sistema del mal, tal y como advirtió Hannah Arendt. Y así, solo la tragedia, ${ }^{8}$ el teatro dentro del teatro puede devolvernos la verdad y el origen de las cosas, con la muerte real de uno de los personajes caracterizado con un discreto bigote hitleriano, en la ópera Brundibár, con la que se pretendía amenizar a los inspectores de la Cruz Roja. Nadie se percata de la muerte real del muchacho que encarna al personaje Brundibár, y que, en medio de la pantomima, al caracterizarse como Hitler por medio de su inconfundible bigote, ha conseguido reestablecer un orden cósmico, pues es Hitler a quien los otros actores matan más allá del plano de realidad en ese escenario que trasciende las coordenadas espacio-temporales para convertirse en espacio ritual, en el lugar sagrado donde se imparte justicia. Después, todo vuelve a ser como antes, es decir, vuelve ese otro simulacro, de terribles consecuencias:

[...] de nuevo el hambre, y la difteria, y la escarlatina; y aún después, los soldados y los trenes

\footnotetext{
${ }^{8}$ Benjamin analiza el papel de la tragedia en el Trauerspiel alemán, cuya herramienta comunicativa fundamental es la alegoría, que desencadena una dialéctica consagrada a la apoteosis barroca. El trágico final al que nos somete el relato de "Hitler regala una ciudad a los judíos" supera a la alegoría y se carga de significado al estar sometida al desvirtuamiento del simulacro. Es el simulacro el que pincha la burbuja alegórica por la que esa muerte nos devuelve al tiempo real. Es el único momento del libro en que, como lectores, nos salimos de ese espacio muerto, aunque las consecuencias sean fatales, pues en esa muerte queda consumado el otro simulacro aún mayor, el sistema ideológico exterminador nazi por el que toda posibilidad de redención, toda capacidad lingüística humana se distorsiona, se deforma, para anunciar su pronta disolución.
}

Mónica Poza Diéguez: "El despertar de los que duermen: Juan Gómez Bárcena y la nueva narrativa española postcrisis" 
y las deportaciones y la infinita espera y las duchas, las duchas al fin. Pero para entonces, ya no habrá delegados que los fotografíen y nada será real. Parecerá sólo un sueño y como tal no dejará ningún rastro; apenas una columna de humo ascendiendo en el aire y un puñado de papeles mecanografiados. Una lista de dieciocho mil setecientos cincuenta y tres nombres que el 10 de noviembre de 1944 el comandante Rahm firmará sin leer, mientras silba distraído los compases finales de Brundibár. (Gómez Bárcena, 2012: 87-88)

Por eso no puede sorprender que el narrador de "Las buenas intenciones" represente la enfermedad, confirmada la ruina del ser. Aquí, la protagonista narra en primera persona el encierro en casa con su madre, a la que inflige todo tipo de torturas, de manera gratuita. Su discurso no es sino el desvarío de la locura, de la psicosis o el alzheimer, en que se ha perdido la identidad, la consciencia del ser, la memoria, y en el que solo existe la oscuridad perversa de la crueldad y el dolor. Sin duda, el desengaño al que se ha visto expuesto el hombre del siglo XXI está presente en este relato que está más allá de las tradicionales categorías de verdad o mentira, incluso del relativismo: "Y por un momento junto las manos y deseo con todas mis fuerzas que mañana sea un día distinto. Un día sin jaquecas ni malos sabores en la boca. Un día en el que haya una única verdad que pueda mirarse a la cara; y esa verdad puede ser cualquier mentira debidamente contada, pues saber lo que era cierto nunca nos sirvió de mucho" (Gómez Bárcena, 2012: 100-101).

Puede afirmarse que la experiencia humana acaba con el relato "Las buenas intenciones", mientras que los últimos cuentos, "2374", "Como si” y "La espera" representan una suerte de advenimiento apocalíptico en que se consuma la extinción de la especie. El relato "Como si" constituye una burbuja en la que queda condensada toda la existencia humana en formato comprimido. El relato queda enmarcado por la frase con la que empieza - "En el principio era el año 2012. Los hombres vivían esperanzados por el pasado sin recordar nada de su futuro: era como si el mundo empezara con ellos" (Gómez Bárcena, 2012: 103) — y por aquella otra con la que acaba — "En el final era el año 2012. Los hombres vivían esperanzados por el pasado sin recordar nada de su futuro: era como si el mundo empezara con ellos" (Gómez Bárcena, 2012: 107)—.

El mundo actual camina sin referentes, a diferencia de lo que sucede en la mayoría de los relatos, se ha perdido la capacidad de trascender o de peregrinar en el decurso histórico. El hombre vive enajenado en un ritmo frenético. El narrador en tercera persona menciona que es posible llegar en doce horas a Hong Kong, lo que marca una gran diferencia con el concepto de "viaje iniciático" que se ha protagonizado en la mayoría de los relatos anteriores. Efectivamente, la alienación del hombre global del siglo XXI es consecuencia, entre otras cosas, de un lenguaje anquilosado, fruto de la modernidad de lo técnico, del relativismo, de la obsesión por alcanzar la verdad a base de fórmulas, una vez que el lenguaje se le ha revelado como fuente de mentiras sin fin. Este hombre del siglo XXI elude su pasado en lo posible y se hace dependiente de su futuro.

Sin embargo, existe un punto de inflexión en el que el tiempo histórico da marcha atrás, se comprime y reduce hasta ser revivido en retorno hasta su origen, y entonces sí, el hombre encuentra el significado, comprende, se libera y perece en tan solo ocho milésimas de segundo:

Instante a instante fue el curso del tiempo. Fueron los eslabones de los días y los años; fue la Historia. Fue la vida rebobinándose como un carrete viejo, como una película que ya se ha visto y apenas nos sorprende. Fue el año 2011 y más tarde el 2010 y el 2009. Fueron miles de efectos, rigurosamente responsables de otros tantos miles de causas. Fue la I Guerra Mundial como consecuencia de los desastres de la segunda. (Gómez Bárcena, 2012: 104)

Mónica Poza Diéguez: "El despertar de los que duermen: Juan Gómez Bárcena y la nueva narrativa española postcrisis" 
En este retroceso temporal, la evolución, lejos de vincularse al racionalismo científico, al desarrollo tecnológico, se vincula a una involución, con lo que queda de manifiesto que la naturaleza humana, origen de las pesquisas y preocupaciones de muchos de los personajes del libro, es puramente química, orgánica: "Cerca del final eran los pedernales, las cavernas, la manada, el cuadrupedismo. Era el vello detrás de las orejas y una laringe demasiado retrasada para permitir el habla. Era el mono, la sábana azotada por el viento y el mono, la felicidad de no ser nunca más un hombre. Y aún más atrás era el final, y el final una gran bola de fuego rojo, y un silencio" (Gómez Bárcena, 2012: 106).

Es imposible no conectar estos últimos fragmentos del relato con algunas producciones culturales. Inevitablemente, acude a la memoria 2001: Odisea en el espacio (1968), de Kubrick, con aquel final en que se le llevaba al espectador al mismo feto observando el surgimiento del cosmos. Pero también recuerda a la canción de los Beatles $A$ Day In The Life (1967), en la que se reproduce la detención del tiempo, la prolongación del instante mismo de la muerte mediante un sonido alargado que simula la explosión de una bomba nuclear. Pues, efectivamente, el origen y el final del mundo se rebelan con un estallido de proporciones monumentales que puede darse por causas naturales o no, tal y como finalmente se deja entrever en el texto:

En el final era la radioactividad. Era el enorme hongo de humo y ceniza de una explosión nuclear y 15 millones de grados centígrados durante exactamente ocho milésimas de segundo. Era la luz, el cráter, la explosión, el vuelo de un misil teledirigido; las sirenas y las alarmas. Era el zumbido de los aviones en el cielo y una declaración de guerra emitida en ciento treinta y ocho idiomas. Eran los himnos, y las banderas, y los discursos. (Gómez Bárcena, 2012: 106)

El hombre, enajenado y desprovisto de lenguaje (a pesar de, y precisamente por los discursos propagandísticos), vacío de toda sustancia histórica, desaparece en el silencio. Aún así, queda tiempo para aquellos que, como antes lo hicieron las momias, pagaron por vivir más allá de la muerte a través del proceso de criogenización, que es lo que se nos cuenta en “2374”. Pero el mundo al que estos humanos-zombie acceden queda reducido a las paredes del sanatorio experimental en el que están confinados. El tiempo, para ellos, se ha convertido en pura anacronía, pues cada cual conoció una época diferente. El contacto con los hombres reales y el mundo real se va distanciando progresivamente debido al notorio fracaso del intento humano por superar la vida, la muerte, el paso inexorable del tiempo, y debido a que ese mundo futuro, ahora presente, es inhóspito. Los Hombres del Presente, a diferencia de los criogenizados, han instaurado una realidad perfecta, sin dolencias ni males, una asepsia feliz, en la que la tristeza ha quedado desterrada. De esta forma el encuentro entre ambos grupos provoca la más paradójica de las situaciones. El hospital se vuelve a convertir en una suerte de campo de concentración, donde los hombres criogenizados llevan, en el limbo, una vida tan paralela a la real que hasta una de ellos llega a quedar embarazada, mientras se anhela la llegada de una muerte que nunca vendrá. Los hombres-zombie, incapaces de adaptarse al mundo fuera del hospital, quedan confinados en una suerte de purgatorio, atrapados por su propio miedo a la libertad:

Una mañana [...] los Hombres del Presente ya no estaban. [...] Y cuando por fin aparecieron, sólo se limitaron a traer cargamentos de comida y agua y ropa, y eso fue todo. No hablaron y evitaron también tocarnos. Sólo dijeron: es peligroso salir, pero hemos descubierto que también es peligroso entrar. Algunos de los nuestros se han suicidado, podéis creerlo; prefieren morir tras pasar demasiado tiempo en vuestro mundo prehistórico. [...] Si queréis

Mónica Poza Diéguez: "El despertar de los que duermen: Juan Gómez Bárcena y la nueva narrativa española postcrisis" 
comprender, deberéis ser vosotros los que nos sigáis al otro lado. Tenéis la decisión en vuestras manos, recordad. Y, al decirlo, señalaron la puerta. Esa puerta que siempre ha permanecido abierta para nosotros. (Gómez Bárcena, 2012: 116)

"La espera", el último relato del libro, constituye un advenimiento apocalíptico en el que la presencia del hombre en el planeta se ha volatilizado. El único vestigio de su existencia son las máquinas y robots que esperan su retorno, a fin de que actualice sus sistemas y repare los daños técnicos. Como antes hiciera el hombre, el robot mira al cielo y espera la venida de El Gran Hombre, como si de un mesías se tratara. Este robot, construido a imagen y semejanza del hombre, reproduce sus temores, sus ansias, sus emociones y elabora un discurso religioso complejo en el que hay lugar para los personajes que aparecieron a lo largo de las páginas del libro: "El Gran Hombre regresará a nosotros con su corona y su cetro, cabalgando aquel misterioso animal tantas veces soñado en nuestras hibernaciones" (Gómez Bárcena, 2012: 123).

Pero, ante todo, este robot anhela descifrar esa escritura sagrada inscrita en cada uno de sus congéneres, y que se le antoja incomprensible, pues en esa escritura está la esencia de su origen. Sin embargo, y al igual que le ocurriera a Urkadunna, el robot es incapaz de entender lo que tales palabras, ahora repetidas a modo de plegarias y oraciones sagradas, significan: "El ciclo se habrá por fin completado. Todo tan fácil como abrir ante el Gran Hombre nuestras tenazas indignas, postrarnos a sus plantas y repetir una vez más sus palabras ininteligibles y pretéritas; gritar por última vez caution, caution, for patent information see operating manual, system error, made in Taiwan, made in Taiwan, keep out, caution. Caution" (Gómez Bárcena, 2012: 123). El mensaje, una fórmula, una instrucción para operar un aparato tecnológico, por completo descontextualizado de su original significado, desarrolla ahora una función religiosa que dota de trascendencia a la máquina. Pero el lenguaje como tal se ha perdido, se ha aniquilado, y todo lo que queda en su lugar es pura chatarra tecnológica, ruinas metálicas silenciosas que imitan, reproducen la vida en una gota de historia coagulada en la que el tiempo se ha detenido para siempre.

\section{Bibliografía}

ASISS GONZÁLEZ, Federico Javier: "El mar y su representación en la literatura cortés. Espacio mítico de caos, incertidumbre, aventura y magia", Roda da fortuna. Revista Eletrônica Sobre Antiguidade e Medievo, IV/1 (2015), 131-156.

BAJTÍN, Mijaíl (1989): Teoría y estética de la novela. Trabajos de investigación. Trads. Helena S. Kriukova y Vicente Cazcarra. Madrid, Taurus.

BAUDRILLARD, Jean (2007): Cultura y simulacro. Barcelona, Editorial Kairós.

BENJAMIN, Walter (2006): "El origen del Trauerspiel alemán”. En Obras completas. Libro 1. Madrid, Ábada, 217-459.

FOUCAULT, Michel (1970): La arqueología del saber. Trad. Aurelio Garzón del Camino. Madrid, Siglo XXI.

FOUCAULT, Michel (2006): Las palabras y las cosas: una arqueología de las ciencias humanas. Madrid, Siglo XXI.

GÓMEZ BÁRCENA, Juan (2013): Bajo Treinta. Madrid, Salto de Página.

GÓMEZ BÁRCENA, Juan (2012): Los que duermen. Madrid, Salto de Página.

PAZ, Octavio (1967): El arco y la lira. México, Fondo de Cultura Económica.

PEDROSA, José Manuel (2003): "La lógica de lo heroico: mito, épica, cuento, cine, Mónica Poza Diéguez: "El despertar de los que duermen: Juan Gómez Bárcena y la nueva narrativa española postcrisis" 
deporte... (modelos narratológicos y teorías de la cultura)". En Mitos y héroes. Urueña, Fundación Joaquín Díaz, 37-63.

VALLS, Fernando: "Hervores y verduras", Babelia, 30 de Noviembre de 2013, 77.

(C) Mónica Poza Diéguez

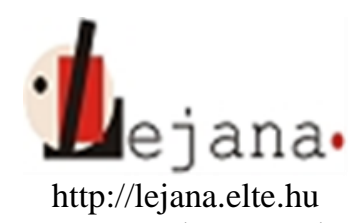

Universidad Eötvös Loránd, Departamento de Español, 1088 Budapest, Múzeum krt. 4/C

Recibido: 22 de marzo de 2016

Aceptado: 01 de mayo de 2016 